\title{
Residual free reactive ion etching of the Bell contact $\mathrm{Ti} / \mathrm{Pt} / \mathrm{Au}$
}

\author{
Gerhard Franz $^{\mathrm{a}, *, 1}$, Robert Kachel ${ }^{\mathrm{b}, 2}$, Stefan Sotier ${ }^{\mathrm{b}}$ \\ ${ }^{a}$ Corporate Research Photonics, Infineon Technologies, D-81730 Munich, Germany \\ ${ }^{\mathrm{b}}$ University of Applied Sciences, D-80335 Munich, Germany
}

\begin{abstract}
The etching of the complete Bell contact consisting of a layer of $\mathrm{Ti} / \mathrm{Pt} / \mathrm{Au}$ was performed in highly reactive plasmas containing $\mathrm{Cl}_{2}$ for $\mathrm{Ti}, \mathrm{PF}_{3} / \mathrm{NF}_{3}$ for $\mathrm{Pt}$, and $\mathrm{Cl}_{2}$ and $/$ or $\mathrm{BCl}_{3}$ for $\mathrm{Au}$. All the constituents of the Bell contact form volatile compounds in either capacitively-coupled low-density plasmas or high-density plasmas generated by electron cyclotron resonance. This is conditio sine qua non for surfaces and sidewalls which have to remain free of any residues. (C) 2002 Published by Elsevier Science Ltd.
\end{abstract}

\section{Introduction}

For p-contacting on III/V compound semiconductors, variations of the Bell contact $\mathrm{Pt} / \mathrm{Ti} / \mathrm{Pt} / \mathrm{Au}$ [1] have evolved to be the most successful. The requirements that a contact has to meet are

1. ohmic contact to the p-doped top region of the semiconductor;

2. good adhesion of this film to surfaces of semiconductor(s) and oxides;

3. ease of bonding, high resistance to corrosion, high elongation to allow thermal expansion mismatch with the substrate;

4. suitability for further high-resolution electroforming.

It is obvious that for these diverging purposes, more than one metal is required. Since the first two qualities can be fulfilled by titanium or chromium, and the last two by gold, which severely degrades the electrical quality of the $\mathrm{p}^{+}$zone, we have to add a third metal to serve as a low-ohmic diffusion barrier.

Titanium or chromium are chosen because of

- their high affinity to oxygen, which makes possible even the reduction of silica, by means of which native

\footnotetext{
*Corresponding author.

E-mail address: gerhard.franz@fhm.edu (G. Franz).

${ }^{1}$ Present address: Department 06, University of Applied

Sciences, 34 Lothstruße, D-80335 Munich.

${ }^{2}$ On leave from Laser Components, D-82140 Olching.
}

oxides can be removed and a good interlink at atomic scale is possible;

- their occurrence in many oxidation states from I to IV for $\mathrm{Ti}$ and I to VI for $\mathrm{Cr}$, with the dramatic consequence that the oxides of the low oxidation levels $\mathrm{Cr}^{\mathrm{II}}$, $\mathrm{Ti}^{\mathrm{II}}$ or $\mathrm{Ti}^{\mathrm{III}}$ have fairly good metallic conductivities (in contrast to e.g. $\mathrm{Al}_{2} \mathrm{O}_{3}$ ), and

- their extremely good gettering behavior: the detrimental effect of reaction products can be neutralized by interstitial dissolution.

With these metals as contact, the lowest contact resistivities challenge the limits of measuring accuracy which are possible with the transmission line method (TLM) or contact hole [2,3]. However, since no suitable etchants for all three layer components are known, the most usual way is to use a simple lift-off technique. In this case, the metal is plated after a process chain which comprises photoresist processing. Hence, the surface which is going to be metallized is prone to contamination. For columnar vertical cavity surface emitting laser (VCSELs), for which a very low contact resistance is required, a direct metal coating on top of a cleaned semiconductor surface is highly recommended. This, in turn, is synonymous with the demand for perfect etching of the quadruple-metal sandwich. Etching means the residue-free removal, which requires the reproducible generation of volatile compounds. Otherwise, fences will build up at the edges of the photoresist, and these can possibly disintegrate and contaminate the surface 

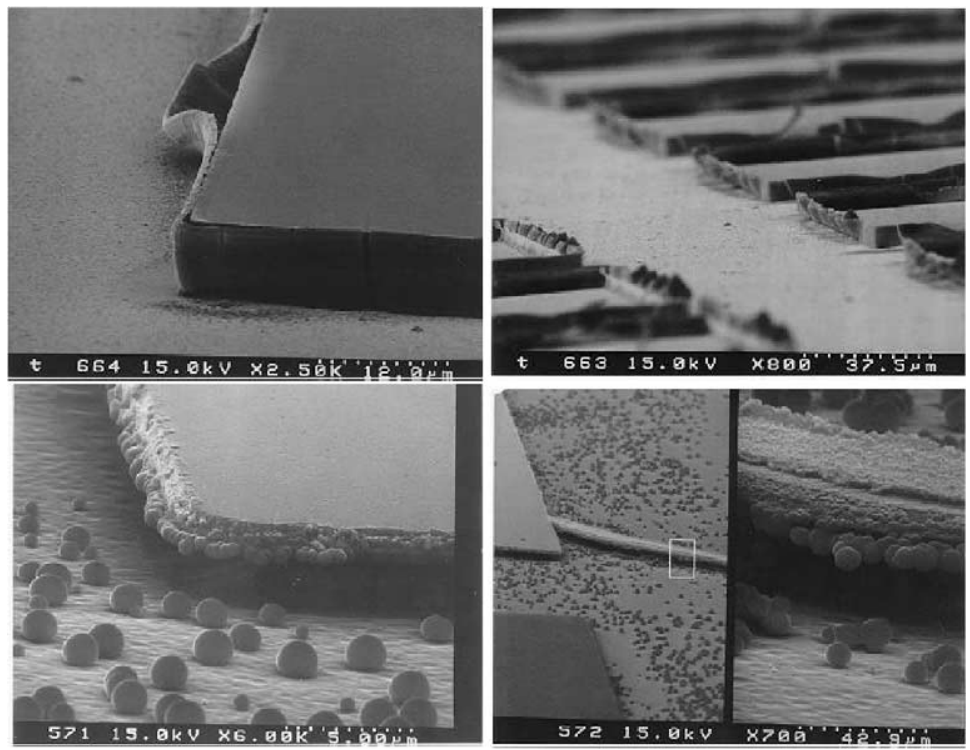

Fig. 1. Various states of gold sputtering with an inert gas: creation of a fence leaning against the photoresist (LHS, top), after removal of the photoresist: the isolated fences (RHS, top), isolated gold spheres and a broken fence... (bottom).

(Fig. 1). Several attempts to etch either gold [4,5] or platinum [6] in chlorine-containing ambients have been reported; but a combined application to actually existing contacts (like the Bell contact or similarly sandwiched metal layers) is still lacking. Hence, in this study we developed a chain of processing steps which are highly selective to each other.

\section{Chemical considerations}

Titanium. Originally, the Bell contact as developed by Lepselter for contacting contact holes in $\mathrm{Si}$, consisted of four metal layers starting with $\mathrm{Pt}$ which reacts with $\mathrm{Si}$ to $\mathrm{Pt}_{5} \mathrm{Si}_{2}$. This has a lot of advantages [1]. Among them are the high electrical conductivity combined with the different color of this compound. In III/V semiconductor processing, the first Pt layer is skipped because $\mathrm{Pt}$ does not react to a stable compound. Therefore, it is common to start with a thin layer of $\mathrm{Ti}(\leqslant 100 \mathrm{~nm})$ on top of the semiconductor surface which must be as clean as possible. Ti is easily etched in an chlorinecontaining ambient like $\mathrm{BCl}_{3}, \mathrm{SiCl}_{4}$, or $\mathrm{Cl}_{2}$ itself. The chemical nature of this process is proven by the surface and the sidewalls, which remain perfectly clean without any redeposit. Moreover, the enhancement of the etch rate compared to pure Ar etching is also remarkable.

Platinum. All simple common etchants completely fail to generate volatile compounds. When heated even to medium temperatures $\left(\geqslant 150^{\circ} \mathrm{C}\right)$, they all decompose to the metal and the counter atom according to the reaction

$\mathrm{PtCl}_{4} \stackrel{\Delta}{\rightarrow} \mathrm{Pt}+2 \mathrm{Cl}_{2}$

Therefore, every progress which has been claimed to date has to be attributed mainly to the enhancement of the etch rate of platinum compared to simple sputtering with argon rather than the generation of a $\mathrm{Pt}$ compound: it is due to the heavier mass of the incident ion (often $\mathrm{Cl}_{2}^{+}$), by which the momentum transfer into the solid is improved [7,8]. This is confirmed by the corresponding communication of redeposits which are proof of the nonvolatility of the claimed platinum compound [6,9-12]. Hence, real chemical strategies have to be applied. These are the following three approaches:

1. Etching with a fluorine source which produces free $\mathrm{F}$. radicals (like $\mathrm{CF}_{4} / \mathrm{O}_{2}$ ) to generate volatile, orange vapors of $\mathrm{PtF}_{6}$.

2. Etching with phosgene, $\mathrm{COCl}_{2}$, or $\mathrm{CO} / \mathrm{Cl}_{2}$ diluted and stabilized with argon to create the volatile carbonyl chloride $\mathrm{Pt}\left[\mathrm{COCl}_{2}\right]_{2}$ [13].

3. Etching with $\mathrm{PF}_{3}$ which generates the volatile compound $\mathrm{Pt}\left(\mathrm{PF}_{3}\right)_{4}$ [14].

The first compound, $\mathrm{PtF}_{6}$, is an orange gas. Its formation is reported at elevated temperatures with elemental fluorine. To avoid this corrosive gas, we chose $\mathrm{NF}_{3}$ which exhibits the lowest energy of formation known for the conventional fluorine sources [15]. As for the second compound, it is known that is formed even from $\mathrm{PtCl}_{2}$ acting with $\mathrm{CO}$ at elevated pressures. Therefore, it should be created under the comparatively 
Table 1

Plasma reactors and experimental conditions for CCP-RIE and ECR-RIE

\begin{tabular}{lll}
\hline & CCP & ECR \\
\hline System & PlasmaLab 90 & $\begin{array}{l}\text { PlasmaLab 90 } \\
\text { with AsTeX double magnet system }\end{array}$ \\
Pump & Pfeiffer TPH 330 & Alcatel 1000 M \\
Volume (l) & 43 & $43+12($ ECR source) \\
Electrode plate: material & $\mathrm{SiO}_{2}$ & $\mathrm{SiO}_{2}, \mathrm{BN}, \mathrm{Al}$ \\
Electrode: diameter $(\mathrm{cm})$ & 25 & 15 \\
Basic pressure (Torr) & $3 \times 10^{-7}-1 \times 10^{-6}$ & $<4 \times 10^{-7}$ \\
Pumping speed (1/s) & 215 & 640 \\
Pressure (mTorr) & 20 & 0.8 \\
Total flow (sccm) & 25 & 40 \\
Reduced pumping speed & 19 & 640 \\
at working pressure & & \\
Bias voltage $(-\mathrm{V})$ & $450-470$ & $25-150$ \\
Temperature $\left({ }^{\circ} \mathrm{C}\right)$ & $75 \pm 3$ & $150 \pm 3$ \\
\hline
\end{tabular}

very mild conditions of a low-pressure plasma, either with equimolar additions of $\mathrm{CO} / \mathrm{Cl}_{2}$ or with phosgene as reactive component. The third compound is the $\mathrm{PF}_{3}$ homologue to the compound $\mathrm{Ni}(\mathrm{CO})_{4}$, which is well known to form the only carbonyl spontaneously from an element. As was shown first by Kruck, $\mathrm{Pt}\left(\mathrm{PF}_{3}\right)_{4}$ is obtained from $\mathrm{PtCl}_{4}$ by applying $\mathrm{PF}_{3}$ at elevated pressures of more than 300 bars $[16,17]$. Compared to these rather hostile conditions, Chatt found out that at atmospheric pressure, the synthesis of volatile cis- $\mathrm{Cl}_{2} \mathrm{Pt}\left(\mathrm{PF}_{3}\right)_{2}$ was possible (bp : $\left.240^{\circ} \mathrm{C}\right)$ [18]. Therefore, this compound is expected to be generated in the highly activated ambient of a high-density, electroncyclotron resonance driven plasma by application of an $\mathrm{PF}_{3}$ containing ambient on metallic platinum. Due to the high energy of the $\mathrm{P}-\mathrm{F}$ bond, $\mathrm{PF}_{3}$ is probably not dissociated, but will attack as an excited molecule or radical.

Gold. The final layer is gold for bonding and longterm stability. Therefore, this is the thickest layer (up to $1 / 2 \mu \mathrm{m}$ thick). This requires an extremely reactive process to avoid hare's ears which develop as redeposit at the sidewalls of a thick mask [19]. In principle, gold can be etched in chlorine-containing plasmas consisting of $\mathrm{Cl}_{2}$ and/or $\mathrm{BCl}_{3}$, leading to volatile $\mathrm{Au}_{2} \mathrm{Cl}_{6}$, but many precautions have to be taken since the vapor pressure of $\mathrm{AuCl}_{3}$ (which dimerizes to $\mathrm{Au}_{2} \mathrm{Cl}_{6}$ as vapor) is very low $[20] .^{3}$ Moreover, it easily decomposes at elevated temperatures to the monochloride, which has an even lower vapor pressure than the trichloride. Hence, there exists a very narrow working window between sufficiently high volatility (lower temperature threshold) and thermal dissociation (upper temperature limit). The etch rate in $\mathrm{BCl}_{3}$ is significantly reduced compared with $\mathrm{Cl}_{2}$

\footnotetext{
${ }^{3} p_{s} \approx 10^{-6}$ Torr at $60^{\circ} \mathrm{C}$ and $\approx 10^{-3}$ Torr at $125^{\circ} \mathrm{C}$.
}

by at least a factor of 3 . Since GaAs/AlGaAs is mainly etched with $\mathrm{BCl}_{3}$ or $\mathrm{SiCl}_{4}$, this behavior is important for further integration into the whole sequence of VCSEL processing. Only in this case, gold can be used as selfadjusting mask for GaAs etching.

\section{Experimental: deposition}

Polished GaAs wafers were coated by means of ebeam evaporation (Leybold system 560) or RF sputtering (Perkin-Elmer 2400). For gold, the first method is superior to the latter one since the grain size is significantly smaller so that the layer can be denoted as amorphous. Formation of striation-free edges is possible only with these layers. To allow for an exact determination of the etch rate, the thickness of the metal films for the trials reported in this study was around half a micron for Ti and Pt and up to $1 \mu \mathrm{m}$ for Au. Titanium can be deposited with a very fine grain size using e-beam evaporation as well as using rf sputtering, and comes along nearly amorphous even at a magnification of some $50,000 \times$. Due to its high melting temperature, platinum is expected to be deposited with a very fine grain size with both methods. This is actually the case.

\section{Experimental: etching}

The etching experiments were carried out applying two Oxford Plasma Technology reactors which are extensively described in previous papers [21,22]. The characteristics of both the systems are compiled in Table 1. For the etching, thick photoresist (AZ 4562, d: between 6 and $7 \mu \mathrm{m}$ ) has been used applying our trilevel technique as reported elsewhere [21]. Every redeposit 

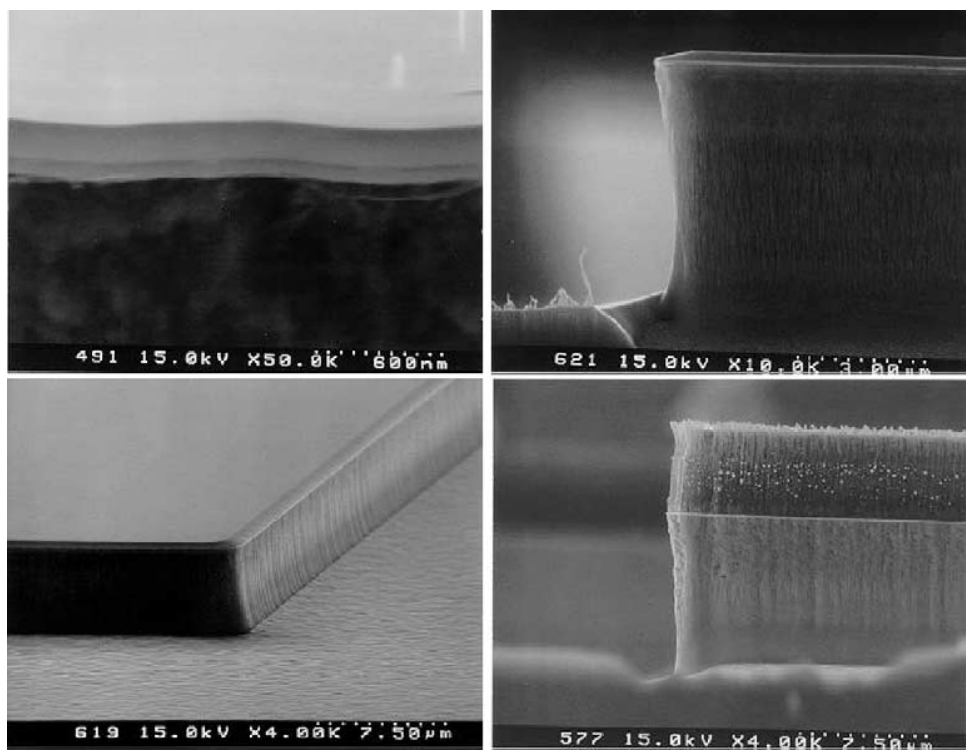

Fig. 2. p-GaAs, topped with Ti/Au (total thickness: $200 \mathrm{~nm}$ ) and a mask with $\mathrm{Al}_{2} \mathrm{O}_{3}$ (top) or thick PR (bottom RHS, trilevel technique [22]). The subsequent etching of underlying GaAs in a high-density plasma of $\mathrm{Cl}_{2} / \mathrm{Ar}$ is carried out without formation of a sidewall polymer $[24] \Rightarrow$ slight undercut in GaAs, but totally free of any residue at the sidewalls of the photoresist.


Fig. 3. Etching of platinum with $\mathrm{NF}_{3}$ does not lead mainly to $\mathrm{PtF}_{6}$. The remnant fence has been deposited at the flank of the photoresist (LHS) and cannot be removed by ultrasonic cleaning (RHS).

will be visible (which is not quite sure with a "hard" mask of dielectric material like $\mathrm{Al}_{2} \mathrm{O}_{3}$ or $\mathrm{Si}_{3} \mathrm{~N}_{4}$, cf. Fig. 2). Hence, the absence of any remnants at the edges of the mask is the crucial criterion whether a process is physically or chemically dominated (cf. Fig. 2, bottom RHS).

For $\mathrm{Ti}$ and $\mathrm{Au}$, best results at etch rates up to $20 \AA /$ min are obtained in $\mathrm{Cl}_{2}$ or $\mathrm{BCl}_{3}$ (even better) with both the kinds of plasmas applied. Etch rates are between 10 and $40 \AA / \mathrm{min}$ which is a good process window for thicknesses not thicker than $4000 \AA$. They are shown with a top layer of alumina in Fig. 2.

The challenge remains the residual-free etching of platinum. With $\mathrm{NF}_{3}$ and $\mathrm{CO} / \mathrm{Cl}_{2}$, the growth of small fences at the rim of the photoresist cannot be avoided.
This means that under the conditions of a high-density plasma, the formation of $\mathrm{PtF}_{6}$ or the carbonyl chloride $\mathrm{Pt}\left[\mathrm{COCl}_{2}\right]_{2}$ is either not exclusively feasible or the formed compounds will decompose at the mask edge (Fig. 3). At least the enhancement ratio of 2 against argon confirms the assumption of $\mathrm{PF}_{6}$ formation (Fig. 4), which is equivalent to the enhancement ratio of pure $\mathrm{PF}_{3}$ (also not always free of residues at the mask flanks).

However, it can be seen from Fig. 5 that adding $\mathrm{PF}_{3}$ to $\mathrm{NF}_{3}$ will lead to the desired result of etching platinum without any remnants $\left(\mathrm{PF}_{3}: \mathrm{NF}_{3}: \mathrm{Ar}=10: 10: 2 \mathrm{sccm}\right.$; $p<1$ mTorr). However, the enhancement factor compared to Ar, equals a maximum of 4 . The etch rates are not high $\left(P_{\mathrm{MW}}: 800 \mathrm{~W}, V_{\mathrm{DC}}:-250 \mathrm{~V} ; T_{\text {surface }}: 205^{\circ} \mathrm{C}\right)$ : about $20-40 \mathrm{~nm} / \mathrm{min}$, but sufficient for a typical 
thickness of $100 \mathrm{~nm}$, so it takes 2-5 min to etch through the platinum section of the metal sandwich.

As expected, the etch rate depends on the gas composition. At equal gas flows of $\mathrm{NF}_{3}$ and $\mathrm{PF}_{3}$, we observe a broad, but distinct maximum. We attribute this behavior to a two-step procedure: in the first step, bond-breaking between platinum atoms by atomic fluorine, followed by an attack of $\mathrm{PF}_{3}$ by which the volatile compound is created (Fig. 6).

It should be pointed out that all the etching has to be accomplished before having sintered the metal layers. Due to interdiffusion, a very stable intermetallic compound, $\mathrm{Ti}_{3} \mathrm{Pt}$, will be formed which even withstands the

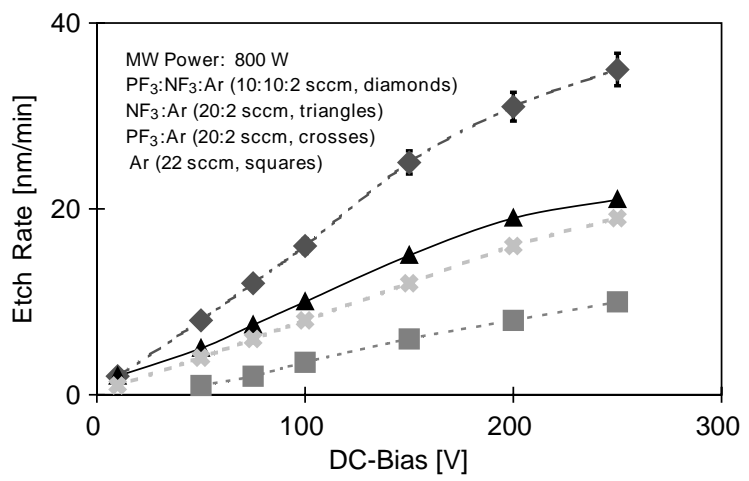

Fig. 4. Pt etch rate as function of gas composition for four gases (three different mixtures and argon, etch rate is parametrized using the most sensitive Pt line at $265.9 \mathrm{~nm}$ ). It can be seen that the etch rate obtained with argon is enhanced by reactive gases $\left(2 \times\right.$ in $\mathrm{NF}_{3},>4 \times$ in $\left.\mathrm{PF}_{3} / \mathrm{NF}_{3}\right)$. This is the crucial criterion for a reactive process. attack of aqua regia and which actually acts as diffusion barrier [23,25]. As has been evident, the reactive ion etching of the Bell contact with consecutive etchants

- Au with $\mathrm{Cl}_{2}$;

- $\mathrm{Pt} \mathrm{NF} 3 / \mathrm{PF}_{3}$;

- Ti with $\mathrm{Cl}_{2}$ or $\mathrm{BCl}_{3}$

is extremely chemical and requires pure metals in a stack of films.

\section{Experimental outlook}

With this etching sequence, we have shown the feasibility of dry etching of the complete Bell contact.

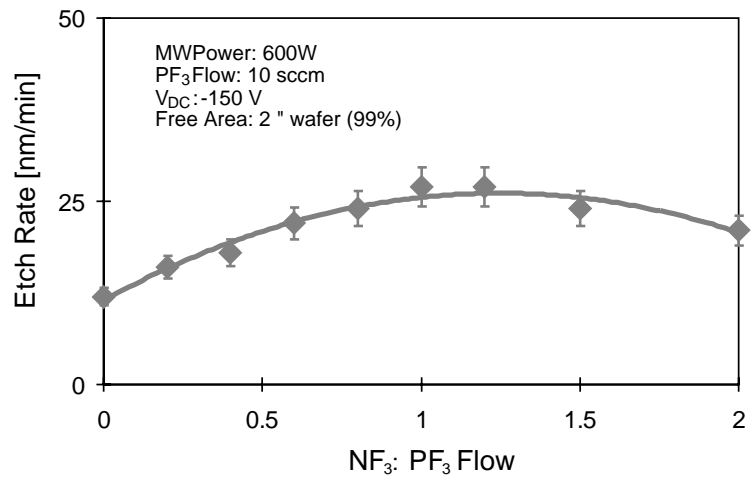

Fig. 6. Pt etch rate as function of gas composition in mixtures of $\mathrm{NF}_{3} / \mathrm{PF}_{3}$. The maximum at equimolar gas flows is referred rather to chemical than physical reasons.
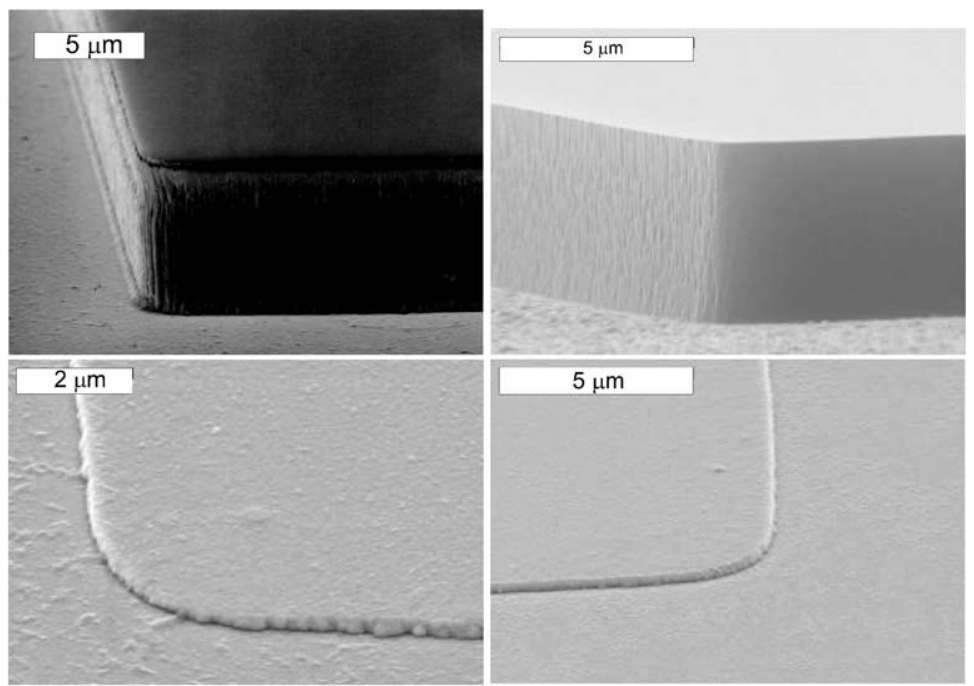

Fig. 5. Comparison of platinum films etched with a $\mathrm{PF}_{3}$-containing ambient (high-density plasma generated with ECR). The PR mask totally lacks any remnants of sputtered platinum (top and middle). After removal of the photoresist, visual inspection of the surfaces shows that the etching does not roughen the surface significantly (bottom, LHS and RHS). 


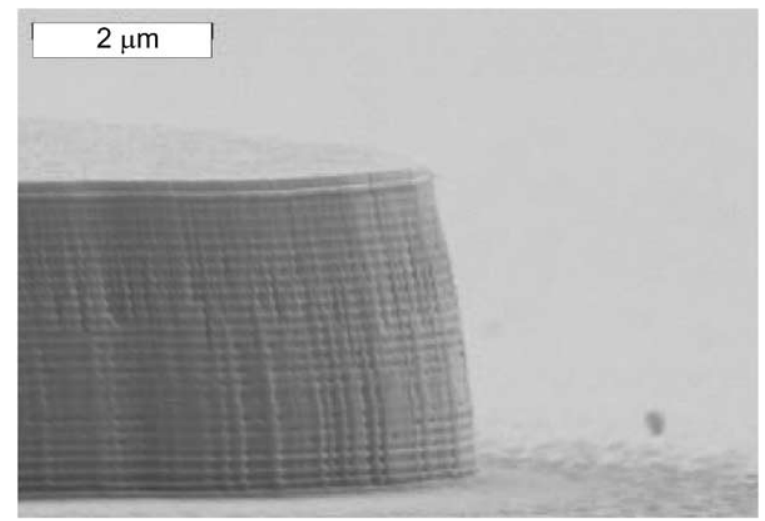

Fig. 7. VCSEL structure as etched with a cap of a platinum (200 $\mathrm{nm}$ in thickness) in the high-density plasma of an ECR discharge $\left(\mathrm{BCl}_{3} / \mathrm{Ar}\right)$.

This has to be integrated into the fabrication process of some optoelectronic devices. We applied the VCSEL structure, protected by a stack of metal layers. As shown in Fig. 7, this stack is highly resistant against $\mathrm{BCl}_{3} / \mathrm{Ar}$ which serves as anisotropic etchant for GaAs/AlGaAs. With this process, we can now choose whether we first deposit the metal layers and etch them subsequently, or apply the common lift-off procedure, which is easier to follow, but prone to contamination of the sensitive surfaces which are to be metallized later on.

\section{Conclusion}

We report on the residual-free etchability of platinum films by application of a high-density plasma containing $\mathrm{PF}_{3} / \mathrm{NF}_{3}$. Trials with $\mathrm{NF}_{3}$ as single possible fluorine source or pure $\mathrm{Cl}_{2}, \mathrm{COCl}_{2}$ or $\mathrm{CO} / \mathrm{Cl}_{2}$ failed. Due to the high energy of formation, $\mathrm{PF}_{3}$ does not dissociate, so it can attack the excited platinum to generate the volatile tetrakis phosphorous trifluoride platinum which is stable enough to pass the dark space sheath of the powered electrode. Therefore, the ambient $\mathrm{NF}_{3} / \mathrm{PF}_{3}$ is the best suited agent to etch $\mathrm{Pt}$ free of residues.

\section{References}

[1] Lepselter MP. Bell System Techn J 1966;45:233.

[2] Loh WM. Modeling and measurement of contact resistances. Technical Report G830-1, Stanford University, Stanford, CA 94305, December 1987. p. 11.

[3] Franz G, Amann M-C. J Electrochem Soc 1993;140:847.

[4] Zarowin CB. Proceedings of the Fourth International Conference on Plasma Chem., vol. 1, 1979. p. 56.

[5] Aldridge FT. J Electrochem Soc 1995;142:1563.

[6] Engelhardt M, Weinrich V, Nagel N, Hartner W. J Vac Sci Technol A 1999;17:1536.

[7] Sigmund P. Phys Rev 1969;184:383.

[8] Sigmund P. Sputtering by ion bombardement: theoretical concepts. In: Behrisch R, editor. Sputtering by particle bombardement I. Berlin: Springer, 1981.

[9] Shibano T, Nakamura K, Takenaga T, Ono K. J Vac Sci Technol A 1999;17:799.

[10] Chiang M-C, Pan F-M, Cheng H-C, Liu J-S, Chan S-H. J Vac Sci Technol A 2000;18:181.

[11] Gutsche MU, Athavale SD, Williams K, Hines D. J Vac Sci Technol B 2000;18:765.

[12] Chung CW, Chung I. J Vac Sci Technol A 2000;18: 835.

[13] Cotton FA, Wilkinson G. Anorganische chemie, 3rd ed. Weinheim, Germany: Verlag Chemie, 1974. p. 750, 751.

[14] Cotton FA, Wilkinson G. Anorganische chemie, 3rd ed. Weinheim, Germany: Verlag Chemie, 1974. p. 761ff., $1095 \mathrm{ff}$.

[15] Cotton FA, Wilkinson G. Anorganische chemie, 3rd ed. Weinheim, Germany: Verlag Chemie, 1974. p. 357f., 496ff.: enthalpy of formation $[\mathrm{kJ} /$ mole]: $\mathrm{F}-\mathrm{F}:-150, \mathrm{~N}-\mathrm{F}:-272$, C-F: -486, P-F: -490 .

[16] Kruck T, Bauer K. Angew Chem 1965;77:505.

[17] Kruck T. Angew Chem 1967;79:27.

[18] Chatt J, Williams AA. J Chem Soc (London) 1951; 3061.

[19] Franz G. Oberflächentechnologie mit Niederdruckplasmen. 2nd ed. Berlin: Springer, 1994. p. 220.

[20] Landsberg A, Hoatson CL. J Less Common Met 1979;22: 327.

[21] Franz G. J Vac Sci Technol A 1998;16:1542.

[22] Franz G, Rinner F. J Vac Sci Technol A 1999;17:56.

[23] Tisone TC, Drobek J. J Vac Sci Technol 1972;9:271.

[24] Franz G, Hösler W, Treichler R. J Vac Sci Technol B 2001;19:415.

[25] Garceau WJ, Fournier PR, Herb GK. Thin Solid Films 1979;60:237. 